\title{
PRESENT CHALLENGES AND SOME CRITICAL ISSUES FOR RESEARCH IN INDUSTRIAL/ORGANISATIONAL PSYCHOLOGY IN SOUTH AFRICA
}

\author{
S ROTHMANN \\ Ian.Rothmann@nwu.ac.za \\ WorkWell: Research Unit for People, Policy and Performance \\ North-West University, Potchefstroom \\ FVN CILLIERS \\ cilliFvn@unisa.ac.za \\ Department of Industrial and Organisational Psychology \\ UNISA, Pretoria
}

\begin{abstract}
The objective of this study was to determine a set of problems and critical issues that researchers in Industrial and Organisational Psychology deem to be important areas for immediate and future enquiry. The changing identity of this field of application is investigated, more relevant paradigms in the study of organisational health and wellness is explored and methods, techniques and interventions suitable to the South African context are suggested. Conclusions are formulated to increase the ability of organisations to work towards economic development, while promoting the wellness and quality of life of employees.
\end{abstract}

Key words

Industrial/Organisational Psychology, identify, tasks, challenges

The objective of this research was to ascertain some of the present challenges and critical issues in Industrial and Organisational Psychology (I/O Psychology) in South Africa, in order to determine the immediate and long term foci for researchers. Firstly, the work context in which employees and employers - as the clients of I/O Psychology - are currently functioning, is analysed. Secondly, the identity of $\mathrm{I} / \mathrm{O}$ Psychology is discussed. Thirdly, the tasks of the I/O psychologist are discussed, with specific reference to implications for research. Lastly, some recommendations for possible future research are formulated.

\section{THE CHANGED CONTEXT OF WORK}

Over the last few decades the occupational arena has undergone remarkable changes. Among these changes are the increased utilisation of information and communication technology, the rapid expansion of the service sector, the globalisation of the economy, the changing structure of the workforce, the increasing flexibility in the world of work, the creation of the 24-hour economy, and the utilisation of new production concepts (e.g. team-based work, tele-work, downsizing, outsourcing and subcontracting) (Barling \& Zacharatos, 2002). Increased flexibility and fragmentation of the workforce also present new challenges for management as they seek to coordinate and control activities (Guest, 2004).

Another factor impacting on the world of work is the pervasiveness and urgency of change. Advances in technology lead to the speeding up of the world of work. Speed and flexibility of response form an important basis for a competitive advantage (Guest, 2004). Compared to 20 years ago, modern employees increasingly work in offices (and less in agriculture or industry) with information or clients (and less with tangible objects), in teams (and less in isolation), and with less job security. The nature of work has also changed from manual to having significantly more mental and emotional demands (Barling, 1999; Turner, Barling \& Zacharatos, 2002).

Many organisations have implemented practices that attempt to reduce costs and increase productivity, which often leads to a mentality that favours profitability over the welfare of people (Turner et al., 2002). The numbers employed in many workplaces are getting smaller. This makes the trade union job of organising the workforce more difficult. It is easier for managers to establish a more personal relationship with employees (Guest, 2004).

Diversity in the workforce is increasing with a less dominant role for the male breadwinner and a growing interest in worklife balance. This is important, especially considering the efforts of organisations to attract and attain high quality employees.

\section{IDENTITY OF INDUSTRIAL/ORGANISATIONAL PSYCHOLOGY}

The above ever changing world of work and its demands imply increased anxiety in all work systems (Miller, 1993). It is therefore hypothesised that organisations need new ways of thinking and operating to effectively deal with these demands. The same is true for I/O psychology focussing on the application of psychology in the workplace (Cascio, 2001).

In 2001, the South African Journal of Industrial Psychology contributed a special edition to review I/O psychology as profession and discipline, its challenges and responses. The general impression created in this edition was that the profession has developed quite substantially in the realm of bringing about (and facilitating) the needed change in organisations, specifically in medium (group/team) and large (organisational) systems (Moalusi, 2001; Pienaar \& Roodt, 2001; Renecle, 2001; Schreuder, 2001; Veldsman, 2001). Less information (or progress) was reported on the development of (1) the profession's role boundaries, and (2) the discipline's (theoretical and professional) development of a clear subject identity, and the understanding of (especially) organisational behavioural dynamics.

Referring to its roots, I/O psychology is defined as an applied division of psychology concerned with the study of human behaviour related to work, organisations and productivity (Cascio, 2001). According to Watkins (2001), the denial of this connection with general Psychology, as is occurring in practice as well as in academia, has lead to an identity crisis, which in practice manifests in role confusion, for example between being a psychologist versus a human resources practitioner. 
This phenomenon can be interpreted as (on the one hand) a seduction by the organisation and its authority structures, and (on the other hand) a disempowerment to apply real and deep psychological knowledge (Stapley, 1996). It is suggested that this confusion be addressed at subject conferences (such as SIOPSA) and university departments of I/O psychology in order to empower practitioners and students alike in order to perform optimally.

I/O psychology may never be able to be called an independent science with its own well thought through perspective on humanity and reality, independent hypothesis and theory formulation, objectivity and sophistication in empirical methodology and data collection (Cilliers, 1991). Matarazzo (1987) stated that in spite of over 100 years of evolution in psychology, there is one core psychology, distinguishing itself from other related discipline such as physics, economy and history. This implies that the subject has informal de facto recognition for specialist parts of Psychology, although it does not enjoy de jure recognition anywhere in the world. The conclusion can thus be made that there is only one Psychology with different fields of application. It is suggested that I/O psychology should keep studying its own identity within the boundaries of general psychology and as such move towards role clarity in various organisational applications.

This suggestion implies working within the boundaries of psychology as a subject. Kruger (1980) describes psychology as a pre-paradigm science, caught up in establishing itself as a science in the postmodern world (see Gergen, 2001). Further, because of its natural sciences methodology and its uncritical usage of constructs of reality from natural sciences, the Cartesian duality is seen as the cancer in psychology (Kruger, 1980). In short, the subject philosophical issues within psychology need to be studied by researchers and practitioners in all fields of psychology in order to render a true professional service to organisations.

I/O psychology mainly operates in the analytical, positivistic paradigm, with an almost exclusively analytical-empirical epistemology (Pietersen, 1989). Its locus of knowledge is involved in the epistemological differentiation between the knower or researcher and the known or employee and organisation, with a value free perspective of the working person (Cilliers, 1991). The range of its research makes the assumption that there is a unique and best description of any chosen aspect of working behaviour. Methodologically there is a preference for quantitative and structured technologies such as questionnaires, tests and structured interviews as opposed to qualitative, unstructured, descriptive case studies, depth interviews and group techniques (Brewerton \& Millward, 2004). Where the latter are used, it is often seen as pilot studies. In terms of the process of knowledge development there is a preference for prediction and control with deductive and differentiated research. Knowledge is measured empirically in predetermined conceptual categories, behavioural models and research hypotheses. Thus, theory is illustrated and validated, rather than defining it. The time perspective is trans-historical with the assumption that findings are the same for all in all circumstances.

It is suggested necessary for researchers and practitioners to study organisational phenomena using quantitative as well as qualitative research designs and to explore the deeper meaning of already established constructs such as leadership and followership, authority, trust, active listening and empathy. This will allow a deeper exploration into organisational dynamics and its effect on employee functioning and wellness. It is interesting that for example Rogers (in Schneider, Bugental \& Pierson, 2001) cautioned that his work should not be trivialized in organizational applications. For example, Kramer (1995) illustrated how active listening is easily forced into a tool to enhance productivity (rather than a skill to build relationships) and Cilliers (1996) illustrated how the concepts of empathy and facilitation are used superficially in training, management and organisational development.

The above identity crises manifests professionally when the industrial psychologist often gets caught up in conflicts between different organisational roles (Campbell, 1995), such as between human resources practitioner and $\mathrm{I} / \mathrm{O}$ psychologist. On the other hand the I/O psychologist often gets confused about who the client in the organisation is - management or employee, management or board member, individual employee or team. Maybe university departments of I/O psychology can selfauthorise more to help resolve this split.

Identity can be defined as a sense of self, a distinctness of differentiation and of the system's own individuality (Huffington, Armstrong, Halton, Hoyle \& Pooley, 2004) Identity is formed in the comparison of the self to 'the other'. Thus, any system seeks and/or constructs an opponent against which it can define itself (such as a sibling or 'the other' department, team or organisation) and then learns what makes the self different or unique. The 'other' functions as a repository object into which the system displaces its internal anxieties, fears and hostilities (Cytrenbaum \& Noumair, 2004). The system tends to rate the self as more favourable and 'the other' as less favourable, especially in conflict situations which could be filled with survival anxiety, needs and behaviour. This may be where one part of the system finds itself in a position of envy, defined as the desire to spoil something good simply because it is good and does not belong to the self. This dynamic may explain the sometimes 'difficult' relationship between I/O psychology and for example clinical psychology and human resources management.

The next step in identity forming refers to projections onto and into 'the other', using the other to serve as the receptacle for uncomfortable anxiety, splits, aggression and other unwanted feelings. It can be hypothesised that this internal split is indicative of external splits which makes identity forming difficult, filled with issues around suspicion, power and de-authorisation. When the system can be mature enough to realise and own the projections, it will be able to develop its identity.

In the organisational setting, the role taken up by leadership is important. A mature identity is formed when leadership is experienced by the system as 'good-enough', meaning a nurturing object, providing containment and emotional need satisfaction. This implies that the group will feel safe, cared for, listened to (which are all aspects of transformational leadership).

For I/O psychology, its empowering will need to focus more on the philosophy underlying the psychology of work and in organisations, including the meaning of work. It is suggested that the systems psychodynamic theory and stance, which originated in depth psychology be used (Bion, 1961; Colman \& Bexton,1975; Colman \& Geller, 1985; De Board, 1978; French \& Vince, 1999; Hirschhorn, 1993; Miller, 1993; Neumann, Kellner \& Dawson-Shepherd, 1997; Obholzer \& Roberts, 1994; Stapley, 1996). Furthermore, the scope of I/O psychology is ever increasing, as is evident in the development of new and challenging interpersonal role roles, such as the facilitation of learning, mentorship, coaching and executive coaching (Huffington et al., 2004; Peltier, 2001; Sperry, 2004). This implies continuous training for the $\mathrm{I} / \mathrm{O}$ psychologist to stay abreast of all relevant applications in theory and in practice. 


\section{THE TASKS OF THE INDUSTRIAL/ORGANISATIONAL PSYCHOLOGIST}

The primary task of $\mathrm{I} / \mathrm{O}$ psychology is the application of psychological principles and research to workplace phenomena. I/O psychologists use the scientific approach, characterised by qualitative observation as well as quantitative measurement and statistics (see Brewerton \& Millward, 2004) to conduct research and intervene in the workplace. Furthermore, they are concerned about the effectiveness of the organisation and the wellness of individuals. Lastly, I/O psychologists operate with an implicit multilevel model, i.e. they recognise that in addition to individual influences on individual behaviour and attitudes, higher-order units such as teams and the organisational context have influence (Ryan, 2003). Therefore, four broad tasks of the $\mathrm{I} / \mathrm{O}$ psychologist are distinguished for the purposes of this paper: 1) explaining individual, group and organisational behaviour and optimising functioning, 2) measuring behaviour and predicting potential, 3) contributing to organisation development, and 4) translating $\mathrm{I} / \mathrm{O}$ research findings and empowering potential users thereof. Examples of specific areas that should be researched by I/O psychologists are given in this section. However, this list is not exhaustive and merely suggest some important research needs.

\section{Explaining individual, group and organisational behaviour and optimising functioning}

I/O psychologists should conduct research about theories and models that could be used to explain individual, group and organisational functioning and the optimisation thereof. Traditionally the health and social sciences have been characterised by a pathogenic paradigm, i.e. an orientation towards the abnormal (Strümpfer, 1990). Knowledge gained by answering this question is then used to find ways of treating and preventing diseases. Diener, Suh, Lucas and Smith (1999) showed that 17 times more scientific articles were published on negative feelings and experiences than on the positive. Myers (2000) found a more favourable ratio of 14:1. Burnout, stress, violations of psychological contracts, job insecurity and downsizing remain popular topics for study in I/O psychology (Turner et al., 2002).

Schaufeli and Bakker (2001) concluded that work is often associated with illness. Research in the Netherlands showed that between $4 \%$ and $10 \%$ of the working population reported serious burnout complaints (Bakker, Schaufeli \& Van Dierendonck, 2000). A recent study among European workers showed that the most common work-related health problems are backache, stress and fatigue. Pienaar (2002) found that 8,64\% of police officers showed serious levels of suicide ideation, while $15 \%$ reported stress-related problems. Levert, Lucas and Ortlepp (2000) reported that $54,9 \%$ of psychiatric nurses in their study in government hospitals experienced a high level of emotional exhaustion. Compared with international norms (Cartwright \& Cooper, 2002), studies in South Africa showed high levels of physical and psychological ill-health for academic and support staff of higher education institutions (Barkhuizen \& Rothmann, 2004; Coetzee \& Rothmann, 2005), employees in the insurance industry (Coetzer \& Rothmann, 2006) and teachers (Jackson \& Rothmann, 2006).

Dysfunctional behaviour frequently occurs in the workplace. For example, American military police recently conducted atrocities with Iraq prisoners (McGeary, 2004). It might be true that they lapsed into sadistic behaviour because they had control over prisoners and they might have felt that their behaviour was sanctioned by an authority figure (Milgram, $1963 ; 1965 ; 1974)$. However, the question arise why such sadistic acts were committed by individuals who are part of a society where the field of Psychology, and specifically I/O Psychology is more advanced than in any other society. In South Africa, a teacher in a secondary school was recently been charged because he showed pornographic pictures to school children (Beeld, 22 May 2004). Furthermore, incidences of sexual harassment, bullying, poor quality work, theft, unsafe actions and unethical behaviour are regularly reported in organisations. However, dysfunctional behaviour is not limited to South African organisations.

In contrast with the above-mentioned argument it seems that work, and more specifically goal-directed, structured activity, translate directly into other mental health outcomes (Kelloway \& Barling, 1991; Turner et al., 2002) and indirectly affect employees' life satisfaction (Hart, 1999; Judge \& Watanabe, 1993). In addition, research (e.g. Kirchler, 1985) regarding the effects of unemployment, showed that a lack of work has detrimental effects, including depression, alcoholism, psychological complaints and even suicide. Therefore, it can be concluded that work could either contribute towards illness or it could have a therapeutic effect.

One possible reason for the overemphasis on negative aspects of work and life is the failure of I/O psychology research to be responsive to the needs of all potential research stakeholders. The prevailing values perspective in I/O Psychology research, emphasising a utilitarian, cost-benefit approach has strongly influenced the framing and interpretation of research questions (Wright \& Wright, 2002). The utilitarian approach regards the achievement of the goals as set forth by one stakeholder group, namely the management of an organisation, as the primary objective of applied research. As a consequence, the employees (as another stakeholder grouping), are considered to be important only to the extent which they are instrumental in fulfilling the organisation's goals. According to utilitarianism, actions and policies should be evaluated on the basis of costs and benefits they impose on the organisation. Therefore, this approach focuses on organisational rather than individual effectiveness.

A consequence of the utilitarian perspective has been that applied research tends to focus unduly on the identification of financial costs to the organisation of distressed, dissatisfied and unhappy employees. The cause of this employee dissatisfaction and unhappiness is typically seen as being deeply imbedded in the emotional maladjustment of the employee, as opposed to aspects of the job itself (Wright, 2003). As a result, the cure for this maladjustment usually involves some type of preventionbased employee therapy (Wright \& Cropanzano, 2000). According to Wright (2003), a short-run focus on the negative may be less than an optimal strategy. While the utilitarian perspective has provided a significant value-addition for those interested in the so called bottom line for business success, it has been much less articulate in proposing an agenda to pro-actively assist employees in their pursuit of healthier and more meaningful lives. Therefore, research must not only focus on how to get employees to be more productive, but also on employee health and wellness.

During 2000, a whole edition of the American Psychologist focussed on positive psychology (Seligman \& Csikszentmihalyi, 2000). According to Seligman (2002), the central objective of positive psychology is to understand and facilitate happiness and subjective well-being. The field of positive psychology at the subjective level is about valued subjective experiences; well-being, contentment, and satisfaction (in the past); hope and optimism (for the future) and flow and happiness (in the present) (Seligman \& Csikszentmihalyi, 2000, p. 5).

The field of positive psychology is rapidly gaining momentum in I/O psychology (Snyder \& Lopez, 2002; Wright, 2003). Erez and Isen (2002) have shown that inducing positive emotional states in people facilitates flexible, effective problem solving, decision making and evaluation of events. Fredrickson's (1998) 'broaden-and-build' theory of positive emotions states 
that positive emotions, including, joy, interest, contentment and happiness all share the ability to 'broaden' an individual's momentary thought-action repertoires. In addition, these positive emotions assists in building the individual's enduring personal resources. The tendency to experience the positive is proposed to be central to one's ability to flourish, mentally prosper and psychologically grow. Therefore, positive emotions have a potentially adaptive and interactive nature and might moderate the relationship between job satisfaction and job performance. Considering the changes employees have to deal with, as well as the deprived background of many South Africans, research about causes, moderators, mediators and effects of positive emotions is of great importance.

Adopting a utilitarian, cost-benefit perspective emphasizing the goal of enhanced workplace performance, Luthans (2002a; $2002 \mathrm{~b}$ ) noted the need for a more relevant, proactive approach to organisational research. He termed this positive organisational behaviour, defined as the study and application of positively oriented human resource strengths and psychological capabilities that can be measured, developed and effectively managed for performance improvement in today's workplace. Therefore, the relationship between happiness and wellness on the one hand, and individual, group and organisational effectiveness on the other hand should be conducted. However, Wright (2003) argues that in addition to a utilitarian perspective, which focuses on the bottom line for business success, the mission of I/O Psychology also includes the pursuit of employee happiness and wellness.

In research with 198000 employees in 36 companies by the Gallup Organization, responses to the following question were analysed: "At work, do you have the opportunity to do what you do best every day?" When employees answered 'strongly agree' to this question, they were $50 \%$ more likely to work in businesses with a low turnover, $38 \%$ more likely to work in productive business units, and $44 \%$ more likely to work in business units with high customer satisfaction scores (Buckingham \& Clifton, 2001). Furthermore, it was found that globally, only 20 percent of employees working in large organisations experienced that their strengths are utilised every day. Also, the longer an employee stays with an organisation and the higher he/she climbs the traditional career ladder, the less likely he/she is to strongly agree that he/she is performing to his strengths. The researchers attributed this finding to the following flawed assumptions about people: 1) each person can learn to be competent in almost anything, and 2) each person's greatest room for growth is in his/her areas of greatest weakness.

Organisations should not only accommodate the fact that employees are different, they must build their enterprises around the strengths of each person. According to Buckingham and Clifton (2001), organisations should change the way they select, measure, develop and channel the careers of individuals. However, this needs change to the following assumptions: 1) each person's talents are enduring and unique, and 2) each person's greatest room for growth is in his/her greatest strength. Research is needed regarding different talents, knowledge and skills that will contribute to individual happiness and organisational performance as well as systems to identify these (Buckingham \& Clifton, 2001). Research linking the six virtues (and 24 strengths) identified by Seligman (2002) to individual wellness and organisational effectiveness should be conducted. These virtues (and strengths) include the following: 1) wisdom and knowledge (curiosity, love of learning, judgement, ingenuity, emotional intelligence and perspective), 2) courage (valour/bravery, perseverance and integrity), 3) humanity and love (kindness, loving and allowing oneself to be loved), 4) justice (citizenship, fairness, equity and leadership), 5) temperance (self-control, prudence and humility), and 6) transcendence (appreciation of beauty and excellence, gratitude, spirituality, forgiveness, humour and passion).

Employees bear some responsibility for making healthy work systems succeed (Turner et al., 2002). Constructs related to proactive role orientations and role-breadth self-efficacy could contribute to wellness and individual effectiveness and efficiency (Strümpfer, 1995). These constructs include amongst others a sense of coherence (Antonovsky, 1987), self-efficacy (Bandura, 1977), optimism (Carver \& Scheier, 2002; Seligman, 2002), subjective well-being and life satisfaction (Diener, Lucas \& Oishi, 2002), resilience (Masten \& Reed, 2002), positive affectivity (Watson, 2002), coping strategies (Stanton, Parsa \& Austenfeld, 2002) and emotional intelligence (Salovey, Mayer \& Caruso, 2002). However, research is needed to evaluate the effects of these constructs in the work situation, the effects of the work situation on these constructs, as well as the effects of interventions directed at building these orientations.

While a positive psychology perspective is necessary, harsh realities exist that contribute to occupational stress, burnout and ill health (Cherniss, 1995). A need exists for behavioural theories and models to integrate positive and negative aspects of human behaviour. For example, Schaufeli and Bakker (2004) developed the Comprehensive Burnout and Engagement (COBE) Model to explain positive and negative behaviour at work. The COBE-model assumes two psychological processes, namely an energetic and a motivational process. The energetic process links job demands with health problems via burnout. The motivational process links job resources via engagement with organisational outcomes. Schaufeli and Bakker (2004) confirmed that job demands were associated with exhaustion, whereas job resources were associated with work engagement. Burnout was related to health problems as well as to turnover intentions, and mediated the relationship between job demands and health problems, while engagement mediated the relationship between job resources and turnover intentions. However, many questions remain about the effectiveness of the model, because their research relied only on self-report measures and cross-sectional data. Furthermore, integrating burnout and work engagement could lead to a new taxonomy which categorise work behaviour according to energy at work (varying from exhaustion to vigour) and identification with work (varying from cynicism to dedication).

Organisational change (including employment equity, layoffs, downsizing, acquisitions, mergers, job relocations and technological innovations at work) have adverse effects on employee well-being. Research should be conducted to determine the effects of such changes on employees in South Africa and assess the effectiveness of interventions to help employees to cope with them (Kalimo, Taris \& Schaufeli, 2003).

As the world is becoming a global village, people are increasingly confronted with diversity, especially in South Africa with its multicultural society. Diversity refers to any difference and includes attributes such as gender, social class, ethnicity, culture, age, sexual orientation and lifestyle. On the individual level the person could have certain limitations making it difficult to deal with diversity (Triandis, 2003). For example, 1) when they process little information, they will have the tendency to use categorisation, and 2) cultures are ethnocentric in nature, that is they use their own culture as standard for judging other cultures. According to Lopez, Prosser, Edwards, Magyar-Moe, Neufeld and Rasmussen (2002, p. 711), research is needed about the following aspects: 1) the magnitude and equivalence of constructs across cultures, 2) the value of religious practices, spirituality and diverse constructions of life meaning, 3) searching for clues to the good life that cultural experiences might provide, and 4) 
clarifying what works in the life of people. Although South African research by Cilliers and May (2002) investigated specific diversity manifestations from a systems psychodynamic stance, more such research is needed to understand how diversity issues change over time and how this influences human relationships and organisational climate.

Few attempts have been made to evaluate the cross-cultural equivalence of constructs such as hope, optimism, self-esteem, happiness, subjective well-being and resilience (Lopez et al., 2002). Most of the studies examining positive psychological constructs have focused on Western samples. Relatively little is known about the concurrent and predictive validity of measures of positive constructs. In a review of national differences, Diener et al., (1999) reported that people living in individualistic cultures have higher levels of satisfaction than those in collectivist cultures. While collectivist cultures give priority to the in-group and define the self in relational terms, individualist cultures encourage independence, attention to personal opinions and feelings and autonomy. Subjective well-being, for example, may therefore be more salient to individualists, and attributes traditionally associated with well-being may not be as relevant for members of collectivist cultures. It is important to recognise that what constitutes a good life may be different in different cultural settings.

While a true cross-cultural perspective on work wellness is lacking, various cross-national studies have been carried out (Golembiewski, Scherb \& Boudreau, 1993; Savicki, 2002). Instead of post-hoc explanations of differences in wellness in multicultural or cross-cultural situations, the testing of a priori formulated cross-cultural hypotheses are needed. For instance, Schaufeli (2003) argued that in individualistic cultures, social exchange relationships between individuals (interpersonal reciprocity) might play a crucial role in causing burnout, whereas in collectivistic cultures social exchange relationships with the group (individual-group reciprocity) might be pivotal. In addition, the effects of stereotypes, prejudice and discrimination on individual wellness and organisational effectiveness should be studied. Furthermore, the role of intercultural communication, cultural differences, minority positions and migration in individual wellness and organisational effectiveness should be investigated.

World-wide there seems to be a tendency for organisations to drift from domestic to global, no matter how small the organisation (Furnham, 1997). One of the consequences of South Africa's becoming part of the global business community is that there has been a vast increase in the number of South Africans taking up assignments outside the country (Hawley, 1999). Research has shown that some expatriate managers who are given foreign assignments end them early because of their poor performance or their inability to adjust to the foreign environment. Many of those who do not return early, function at a low level of effectiveness (Fish \& Wood, 1997). Congruent to the strategic importance of assignments, failure of an expatriate may be costly and even detrimental to the future of a multinational company in a host country (Gregersen \& Black, 1990). Thus, research is needed regarding factors related to success of expatriate assignments.

Leadership is another area that should be researched in South Africa. Although few academics or business practitioners would argue with the notion that effective leadership contributes to the positive health of an organisation, little research has focussed on the effects of leadership on individual wellness (Turner et al., 2002). This has resulted in a limited appreciation of the value of positive leadership within the context of organisations. Transformational leadership has the potential for enhancing wellness. This occurs when leaders increase followers' awareness of the mission/vision towards which they are working, choose what is right rather than what is simple or expedient, display inspirational motivation and intellectual stimulation, and manifest individualised consideration. Studies (e.g. Barling, Kelloway \& Weber, 1996) showed that transformational leadership leads to higher performance and employee morale, although its relationship with performance is mediated by affective organisational commitment. However, superior performance would require transformational leadership to be present above and beyond constructive interactions between employees and management that constitute good management (Turner et al., 2002). The relatively new concepts (Huffington et al., 2004) of containment leadership (stimulating exploration and curiosity) and pro-tainment (including organisational reframing and creativity) need to be researched for its potential in facilitating employee wellness.

Work/life balance is also an important research topic in South Africa. Keyser and Dickinson (2002) introduced the concept of organisational schizophrenia as a condition that exists in organisations due to the opposing pulls of employees' need to have a personal life and the organisation's need to have employees accessible and working on an almost constant basis. More demands (including an increase in the average work hours) are placed on employees in their workplaces. Geurts, Kompier, Roxburgh and Houtman (2003) found that work-home interference mediated the relationship of workload with depressive mood and health complaints and moderated the relationship with work-related negative affect. It seems that workload exerts its negative effects on wellness through a process of spillover of negative load-effects that impede recovery during non-working hours. Research into emotional work demands and work-home balance is necessary (Kompier, 2002). On the other hand, employees may not just suffer from excessive work demands, but may as well benefit from a work situation that contains support or resources that are relevant to meeting demands.

Sonnentag (2003) studied the work-related outcomes of recovery during leisure time. She found that day-level recovery was positively related to day-level work engagement and day-level proactive behaviour. The results of her study showed that experiences outside work are crucial for feelings and behaviour at work. However, it is not clear what the preconditions of recovery on a specific day are. It is also not clear which factors mediate or moderate the relationship between recovery on and work engagement or proactive behaviour. The long-term effects of recovery should also be researched.

Every year more young people are entering the labour market, seeking jobs. At the same time South Africa is struggling with an enormous unemployment rate. For a variety of reasons, many of the job seekers in South Africa have attained very low educational levels. Research is needed on the best way to implement career counselling services and life skills training for job seekers. The dilemma facing organisations is that they need to employ job seekers that possess the necessary technical, business and scientific skills to face the challenges posed by the business environment. The fact that many job seekers do not possess the necessary skills implies that research is needed on how to improve the employability of applicants. Because of the use of technology and of the skills required to use the technology, many workers are nowadays less subject to management control systems. This means that non-supervisory personnel need to acquire 'management' skills, which include self-management skills, interpersonal skills and problem solving skills.

Paid work contributes to mental health and affects employees life satisfaction. As a consequence, unemployment has been shown to have detrimental effects for well-being. Individual coping behaviour associated with unemployment depends on certain objective characteristics such as age, level of education, and length of unemployment (Warr, 1984). De Witte (1994) distinguished a typology of coping behaviours, which integrates 
meaningful patterns of unemployment experiences and adaptive responses, including the attitudes, expectations and experiences of the unemployed (e.g. work motivation, well-being and search behaviour). Research regarding unemployment could be used to plan and implement policies in organisations.

It is not only sufficient to investigate which themes in $\mathrm{I} / \mathrm{O}$ psychology should be researched. It is also necessary to consider how research should be done. For instance, Kompier (2002) analysed various I/O psychology studies and recommends the following: 1) more general research is not needed, 2) further expansion of the number of studies based on cross-sectional study designs and on employees' self-reports has little added value, and 3 ) researchers should not try to compensate for weak study designs by increasing the number of sophisticated statistical analyses. There is a need for better designs, such as longitudinal and experimental designs and better quality data (Breverton \& Millward, 2004).

More qualitative designs and work across boundaries of paradigm and theory should also be considered. For example the inclusion of the systems psychodynamic stance (Miller, 1993; Obholzer \& Roberts, 1994) would explain the relevant qualitative and deeper, unconscious behaviour. The application of this model often helps in understanding organisational stuckness, non-movement and anti-task behaviour in for example change, transformation and diversity issues.

\section{Measuring behaviour and predicting potential}

Over the years psychological tests have become essential tools for implementing change. The term test refers to group and individually administered standardised measures of aptitudes, achievement, intelligence, personality, social, language, perception and motor skills (Oakland, 2004). Strong evidence exists to support the merit of tests for monitoring children in the educational system, providing policy-makers with information for decision making, aiding psychologists in the individual screening and diagnostic process, credentialing and licensing candidates in professions and specialties, and providing organisations with data for employee selection, promotion and evaluation of training (Hambleton \& Oakland, 2004).

The cultural appropriateness of psychological tests and their usage were placed in the spotlight with the promulgation of the new Employment Equity Act 55 of 1998, Section 8 (Government Gazette, 1998), which stipulates that: "Psychological testing and other similar assessments are prohibited unless the test or assessment being used - (a) has been scientifically shown to be valid and reliable, (b) can be applied fairly to all employees; and (c) is not biased against any employee or group." Despite the multicultural nature of our society, psychological test development in South Africa has historically been characterised by the development of tests for separate cultural and/or language groups (Claassen, 1997; Foxcroft, 1997). While past apartheid policies and legislation shaped the way in which test development was approached until the 1990s, it is somewhat disturbing to note that subsequent to apartheid's demise, very few new culturally relevant tests have been developed that can be applied to a diverse range of cultural and language groups in South Africa.

Personality variables and issues related to their use, especially in work settings have generated a vast amount of interest, research and publications. The importance of personality to I/O Psychology is now apparent with meaningful relationships between personality variables and criteria, such as job satisfaction, supervisory ratings, the development of job-specific criteria, counterproductive behaviour, and organisational citizenship. Criterion-related validities for predicting work-related constructs reveal the importance of personality variables in understanding and predicting work performance. Various methodological questions should be raised when applying personality assessment, namely 1) is paper-and-pencil testing familiar to people in a specific culture? 2) are respondents proficient in reading English? 3) is the translation done accurately? 4) is the translated test equivalent to the original test? 5) are there cross-cultural differences in the means and distributions of test scores? 6) how can cross-cultural differences in test scores be interpreted? (Cheung, 2004).

Currently, none of the available personality tests used in South Africa have been found to provide a reliable and valid picture of personality for all cultural (and language) groups in this country. Meiring, Van de Vijver, Rothmann and Barrick (2005) clearly demonstrated that psychological instruments imported from abroad could have a limited suitability for South Africa. It was only after a series of item adaptations that acceptable psychometric properties were found. In recent years more attention has been paid to the issue of equivalence of tests for the multicultural South-African context (e.g. 1991; Meiring et al., 2005). The results of the examinations were not unequivocally positive. Meiring et al. reported very low internal consistencies for the 15FQ (see Tyler, 2002) in all South-African language groups. In what is known as an etic approach, the currently used tests have been imported from elsewhere (often from Anglo-Saxon countries), while emic personality constructs important in Africa have been omitted. The Chinese Personality Assessment Inventory (CPAI) is cited as an example of indigenous measures that have identified culturally salient dimensions. The unique Interpersonal Relatedness factor of the CPAI measures an aspect of personality which has been absent in the personality tests that are used all over the world (Cheung, 2004). The development of a personality test in South Africa might contribute to the development of an indigenous personality theory.

In the social, behavioural, and medical sciences self-report questionnaires are often used as an efficient and inexpensive method for data collection. However, asking respondents to report on their own personality, attitudes, or behaviour entails a number of problems. Respondents often show tendencies to answer according to certain patterns (response styles) lowering the validity of instruments. The most salient response style is social desirability, that is the tendency of participants to respond to questionnaire items in line with societal norms about what is appropriate (Van Hemert, 2003).

Research regarding the reliability, factorial validity, and predictive validity of assessment tools is needed. Furthermore, more research is needed on the equivalence and bias of assessment tools used in South Africa. Van de Vijver and Leung (1997) make a hierarchical distinction of three types of equivalence, namely 1) construct equivalence, which indicates the extent to which the same construct is measured across all cultural groups studied, 2) measurement unit equivalence which can be obtained when two metric measures have the same measurement unit but have different origins, and 3) scalar equivalence which can be obtained when two metric measures have the same measurement unit and the same origin. Equivalence cannot be assumed but should be established and reported in each study (Van de Vijver \& Leung, 1997). Item bias should also be computed. An item is an unbiased measure of a theoretical construct if persons from different cultural groups have the same average score on the item (Van de Vijver \& Leung, 1997). Item bias can be produced by sources such as incidental differences in appropriateness of the item content and inadequate item formulation.

\section{Contributing to organisational development}

To contribute to organisational development, researchers and practitioners need to conceptualise organisational effectiveness and develop measures thereof. These measures could then be used as criteria in concurrent and predictive validity studies. 
Also, with the current focus on effectiveness in organisations (including state departments), organisation diagnostic measuring instruments (focussing on organisational culture and climate) should be researched.

The effects of individual, group and organisational interventions directed at organisational effectiveness and efficiency should be researched (Rothmann, 2003). Traditionally there was too much focus on changing the individual, without considering the situation in which individuals find themselves (Kompier \& Cooper, 1999). One of the most important ways of improving the experience of work is to design jobs such as to encourage workers to engage actively with their tasks and work environment (Turner et al., 2002). By providing workers with autonomy in performing their jobs, challenging work, and the opportunity for social interaction, employee effectiveness and feelings of competence are maximised. The following work design models should be evaluated in the South African context (Kompier, 2003): 1) the job characteristics model, 2) the Michigan organisation stress model, 3) the job demands-control model, 4) the socio-technical approach, 5) the action theoretical approach, 6) the effort-reward imbalance model, and 7) the vitamin model.

The effectiveness and potential cost benefits of interventions (e.g. redesigning jobs and implementing teamwork) have not been rigorously evaluated (Kompier \& Cooper, 1999). The few rigorous studies that were conducted showed significant improvements in employee satisfaction and motivation levels, but productivity outputs improved minimally.

Organisational development interventions in general and interventions to influence culture and values should be implemented to contribute to healthier work places. Furthermore, psycho-educational programmes should be developed and presented to combat burnout and to promote work engagement (Kompier \& Cooper, 1999).

New technology (including information technology and new production methods) are continuously introduced by organisations. I/O psychologists should be involved in interdisciplinary teams who plan the implementation of new technology. From a systems perspective it is necessary that changes in the task subsystem (e.g. technology) must be accompanied by changes in the psycho-social subsystem (knowledge, skills, attitudes and values) (Robbins, Odendaal \& Roodt, 2003).

Four dimensions of organisational results should be evaluated when measuring the effects of work wellness interventions, namely financial results, time and personnel resources, customer satisfaction and health and safety (Kompier \& Cooper, 1999). Financial results are taken from an organisation's profit and loss account and balance sheet. Time and personnel resources include hours worked, personnel statistics and personnel reports, which show the levels of staffing and competency that have been used to achieve the financial result. Measurement of customer satisfaction show how effective an organisation has been in satisfying customer's requirements. Health and safety include the physical and psychological working environment, stress, burnout, health, work engagement and job satisfaction. Study of the effectiveness of interventions will require an interdisciplinary approach.

\section{Translating research findings and empowering potential users thereof}

Although a large body of research findings exist, potential users often do not react on them. This might be attributed to a lack of knowledge of research findings, a lack of implementation skills, a lack of motivation and/or limitations created by the prevailing organisational culture. According to Watkins (2001), many industrial leaders uphold dysfunctional paradigms which may profoundly diminish the effectiveness of I/O Psychology teaching and research. Reacting to the opinions of industrial leaders, without at least considering organisational success factors to support their reasoning, may potentially be devastating to the subject.

\section{RECOMMENDATIONS}

Next, recommendations are made regarding some important research topics for I/O psychologists.

I/O psychology should study its changing identity and dynamics constantly in order to stay relevant in the world of work. This includes responding in a sensitive manner towards organisational efforts to seduce practitioners to become involved in administration and mechanistic inputs. Research designs should include more qualitative designs across boundaries of paradigm and theory to fit post-modern thinking (Camic, Rhodes \& Yardley, 2003). For example, the inclusion of the systems psychodynamic stance (Miller, 1993, Cytrynbaum \& Noumair, 2003) would explain the relevant qualitative, deep and unconscious behaviour manifesting in organisational change, transformation, mergers, acquisitions, diversity management and the symptoms of stuck-ness, pain and anti-task behaviour associated therewith.

The philosophy underlying the Psychology of work and in organisations, including the meaning of work, should be studied. Also, new theories to conceptualise individual, group and organisational behaviour in the work context, based on a continuum of human behaviour (from negative to positive) as expressed in multicultural and cross-cultural environments should be developed and tested. Causal models of behaviour in multicultural and cross-cultural work contexts should be developed and tested. The effects of organisational factors (job demands and job resources) on well-being, work/life balance, as well as the moderating or mediating effects of personality characteristics and strengths should be studied in longitudinal and/or experimental designs. Strategies to improve the work/non-work interface should be researched. Furthermore, the effects of individual wellness on organisational outcomes such as performance, labour turnover, safety behaviour and absenteeism should be studied.

Diversity represents another important area of research for industrial psychologists. The effects of stereotypes, prejudice and discrimination on individual wellness and organisational effectiveness should be studied. Furthermore, research is needed regarding the role of inter-cultural communication, cultural differences, minority positions and migration in individual wellness and organisational effectiveness. Research is needed regarding the reliability, validity, equivalence and bias of psychological tests in the multicultural context of South Africa. These tests could provide policy-makers with information for decision making, aid psychologists in the individual screening and diagnostic process and provide organisations with data for employee selection, promotion and evaluation of training. While the cultural appropriateness of internationally developed psychological tests should be evaluated, new tests should be developed based on South African circumstances. The use psychological tests to predict individual well-being and organisational effectiveness should also be researched.

Strengths and psychological capabilities that can be measured, developed and effectively managed for performance improvement in the workplace should be studied. Such strengths and capabilities include sense of coherence, self-efficacy, optimism, subjective well-being and life satisfaction, resilience, positive affectivity, coping strategies and emotional intelligence. Research regarding the ways organisations could select, measure, develop, and channel the careers of individuals based on their strengths should be conducted. The magnitude and equivalence 
of constructs across cultures, the value of religious practices, spirituality and diverse constructions of life meaning, and clues to the good life that cultural experiences might provide should also be studied.

It is clear that the employment relationship has changed. Therefore, changes in psychological contracts and the effects thereof on individual wellness and organisational effectiveness should be studied. The effects of changes in the psychological contract on job security levels, factors which contribute to job insecurity, moderators and/or mediators, as well as outcomes thereof should be investigated. Research is needed on the best way to implement career counselling services and life skills training for job seekers. Furthermore, experiences of unemployment in South Africa should be investigated to determine its impact on the well-being, attitudes and coping behaviours of unemployed individuals in a multicultural context. Psychological profiles of unemployed individuals of different demographic groups could be used as basis for planning and implementing policies (regarding counselling services, life skills programmes, training programmes and job creation programmes) to solve problems related to the unemployed.

The effectiveness of primary, secondary and tertiary level interventions to promote individual, group and organisational effectiveness should be investigated. Research is needed conceptualise organisational effectiveness and to develop reliable and valid indicators thereof.

Careful consideration should be given to the selection of research designs. Cross-sectional designs might be useful in developing and standardising psychological tests. However, more studies based on cross-sectional study designs and on employees' self-reports has little added value. Relevant and applicable statistics should be used. Better research designs (such as longitudinal and experimental research designs) are needed. It is also important that industrial psychological researchers collaborate with occupational physicians, psychiatrists, psychologists, engineers as well as fellow scholars from such fields as epidemiology, physiology, economics and business administration. However, as a prerequisite for collaborating with researchers and/or practitioners from other disciplines, it is necessary that $\mathrm{I} / \mathrm{O}$ Psychology solves its identity issues.

\section{REFERENCES}

Antonovsky, A. (1987). Unraveling the mystery of health: How people manage stress and stay well. San Francisco: Jossey-Bass.

Bakker, A., Schaufeli, W.B. \& Van Dierendonck, D. (2000). Burnout: Prevalentie, risicogroepen en risicofactoren. In: I.L.D. Houtman, W.B. Schaufeli \& T. Taris (Eds.), Psychische vermoeidheid en werk: Cijfers, trends en analyses (pp. 65-82). Alphen a/d Rijn: Samsom.

Bandura, A. (1977). Self-efficacy: Toward a unifying theory of behaviour change. Psychological Review, 84, 191-215.

Barkhuizen, N. \& Rothmann, S. (2004, March). Burnout of academic staff in a higher education institution. Paper presented at the $2^{\text {nd }}$ South African Work Wellness Conference, Potchefstroom, South Africa.

Barling, J. (1999). Changing employment relations: Empirical data, social perspectives and policy options. In D.B. Knight \& A. Joseph (Eds.), Restructuring societies: Insights from the social sciences (pp. 59-82). Ottawa: Carlton University Press.

Barling, J., Kelloway, E.K. \& Weber, T. (1996). Effects of transformational leadership training on attitudinal and financial outcomes: A field experiment. Journal of Applied Psychology, 81, 827-832.

Bion, W.R. (1961). Experiences in groups. London: Tavistock Publications.
Brewerton, P. \& Millward, L. (2004). Organisational research methods. London: Sage.

Buckingham, M. \& Clifton, D.O. (2001). Now, discover your strengths. New York: The Free Press.

Camic, P.M., Rhodes, J.E. \& Yardley, L. (2003). Qualitative research in Psychology. Expaning perspectives in methodology and design. Washington: APA.

Campbell, D. (1995). Learning consultation. A systemic framework. London: Karnac.

Cartwright, S. \& Cooper, C.L. (2002). ASSET: An Organizational Stress Screening Tool - The management guide. Manchester, UK: Robertson/Cooper Ltd.

Carver, C.S. \& Scheier, M.F. (2002). Optimism. In C.R. Snyder \& S.J. Lopez (Eds.). Handbook of positive psychology. (pp. 231-243). Oxford, UK: Oxford University Press.

Cascio, W.F. (2001). Knowledge creation for practical solutions appropriate to a changing world of work. South African Journal of Industrial Psychology, 27 (4), 14-16.

Cherniss, C. (1995). Beyond burnout: Helping teachers, nurses, therapists and lawyers recover from stress and disillusionment. New York: Routledge.

Cheung, F.M. (2004). Use of western and indigenously developed personality tests in Asia. Applied Psychology: An International Review, 53, 173-191.

Cilliers, F. (1991). Die veranderende rol van die Bedryfsielkunde in Suid-Afrika. Pretoria: Unisa.

Cilliers, F. (1996). Facilitator training in South Africa. In R. Hutterer, G. Pawlowsky, P.F. Schmid \& R. Stipsits (Eds.), Client centred and experiential psychotherapy. Frankfurt am Main: Peter Lang.

Cilliers, F. \& May, M. (2002). South African diversity dynamics. Reporting on the 2000 Robben Island Diversity Experience. A Group Relations event. SA Journal of Labour Relations, 26 (3), 42-68.

Claassen, N.C.W. (1997). Cultural differences, politics and test bias in South Africa. European Review of Applied Psychology, 47, 297-307.

Coetzee, S.E. \& Rothmann, S. (2005). Occupational stress in a higher education institution in South Africa. South African Journal of Industrial Psychology, 31 (1), 47-54.

Coetzer, W.J. \& Rothmann, S. (2006). Occupational stress and strain of employees in an insurance company. South African Journal of Business Management.

Colman, A.D. \& Bexton, W.H. (1975). Groups relations reader 1. Jupiter: A.K. Rice Institute.

Colman, A.D. \& Geller, M.H. (1985). Group relations reader 2. Jupiter: The A.K. Rice Institute.

Cytrynbaum, S. \& Noumair, D. (2004). Group relations reader 3. Jupiter: A.K. Rice Institute.

De Board, R. (1978). The psychoanalysis of organisations. London: Routledge.

De Witte, H. (1994). Differences in psychological well-being of short-term and long-term unemployed: A cross-sectional study in the Flanders, Belgium. Katolieke Universiteit Leuven, Belgium.

Diener, E., Lucas, R.E. \& Oishi, S. (2002). Subjective well-being: The science of happiness and life satisfaction. In C.R. Snyder \& S.J. Lopez (Eds.). Handbook of positive psychology. (pp. 63-73). Oxford, UK: Oxford University Press.

Diener, E., Suh, E.M., Lucas, R.E. \& Smith, H.I. (1999). Subjective wellbeing: Three decades of progress. Psychological Bulletin, $125,267-302$.

Erez, A. \& Isen, A.M. (2002). The influence of positive affect on the components of expectancy motivation. Journal of Applied Psychology, 87, 1055-1067.

Fish, A. \& Wood, J. (1997). Managing spouse/partner preparation and adjustment. Personnel Review, 26, 445-466.

Foxcroft, C.D. (1997). Psychological testing in South Africa: Perspectives regarding ethical and fair practices. European Journal of Psychological Assessment, 13, 229-235.

Fredrickson, B.L. (1998). What good are positive emotions? Review of General Psychology, 2, 300-319. 
French, R. \& Vince, R. (1999). Group relations, management, and organization. New York: Oxford University Press

Furnham, A. (1997). The psychology of behaviour at work: The individual in the organization. Sussex, UK: Psychology Press.

Gergen, K.J. (2001). Psychological science in a postmodern context. American Psychologist, 56, 803-813.

Geurts, S.A.E., Kompier, M.A.J., Roxburgh, S. \& Houtman, I.L.D. (2003). Does work-home interference mediate the relationship between workload and well-being? Journal of Vocational Behavior, 63, 532-559.

Golembiewski, R.T, Scherb, K. \& Boudreau, R.A. (1993), Burnout in cross-national settings: Generic and model-specific perspectives. In W.B. Schaufeli, C. Maslach \& T. Marek (Eds.), Professional burnout: Recent developments in theory and research. Series in applied psychology: Social issues and questions (pp. 217-236). Washington: Taylor \& Francis.

Government Gazette. (1998). Republic of South Africa, Vol. 400, no. 19370, Cape Town, 19 October 1998.

Gregersen, H.B. \& Black, J.S. (1990). A multifaceted approach to expatriate retention in international assignments. Group and Organizational Studies, 15, 461-485.

Guest, D.E. (2004). The psychology of the employment relationship: An analysis based on the psychological contract. Applied Psychology: An International Review, 53, 541-555.

Hambleton, R.K. \& Oakland, T. (2004). Advances, issues and research in testing practices around the world. Applied Psychology: An International Review, 53, 155-156.

Hart, P.M. (1999). Predicting employee life satisfaction: A coherent model of personality, work and non-work experiences, and domain satisfaction. Journal of Applied Psychology, 84, 564-584.

Hawley, K. (1999). The expatriate departure planning period. Management Today, 15 (3), 34-35.

Hirschhorn, L. (1993). The workplace within: Psychodynamics of organizational life. Cambridge: MIT Press.

Huffington, C., Armstrong, A., Halton, W., Hoyle, L. \& Pooley, J. (2004). Working below the surface. The emotional life of contemporary organisations. London: Karnac.

Jackson, L.T.B. \& Rothmann, S. (2006). Occupational stress of teachers in the North West Province of South Africa. South African Journal of Education.

Judge, T.A. \& Watanabe, S. (1993). Another look at the job satisfaction-life satisfaction relationship. Journal of Applied Psychology, 78, 939-948.

Kalimo, R., Taris, T.W. \& Schaufeli, W.B. (2003). The effects of past and anticipated future downsizing on survivor wellbeing: An equity perspective. Journal of Occupational Health Psychology, 8, 91-109.

Kelloway, E.K. \& Barling, J. (1991). Job characteristics, role stress and mental health. Journal of Occupational Psychology, 64, 291-304.

Keyser, D. \& Dickinson, F. (2002). The schizophrenic organization. The Industrial-Organizational Psychologist, 39 (4), 39-41.

Kirchler, E. (1985). Job loss and mood. Journal of Economic Psychology, 6 (1), 9-25.

Kompier, M. \& Cooper, C. (1999). Preventing stress, improving productivity. London: Routledge.

Kompier, M. (2002). The psychosocial work environment and health: What do we know and where should we go? Scandinavian Journal of Work Environment Health, 28 (1), 1-4.

Kompier, M. (2003). Job design and well-being. In M.J. Schabracq, J.A.M. Winnubst \& C.L. Cooper (Eds.), The handbook of work and health psychology (pp. 429-454). London: Wiley.

Kramer, R. (1995). Carl Rogers meets Otto Rank: The discovery of relationship. In T. Pauchant \& Associates (Eds.), In search of meaning. San Francisco: Jossey-Bass.

Kruger, D. (1980). Het die Sielkunde as wetenskaplike projek misluk? South African Journal of Psychology, 11 (1), 6-17.
Levert, T., Lucas, M. \& Ortlepp, K. (2000). Burnout in psychiatric nurses: Contributions of the work environment and a Sense of Coherence. South African Journal of Psychology, $30,36-43$

Lopez, S.J., Prosser, E.C., Edwards, L.M., Magyar-Moe, J.L., Neufeld, J.E. \& Rasmussen, H.N. (2002). Putting positive psychology in a multicultural context. In C.R. Snyder \& S.J. Lopez (Eds.). Handbook of positive psychology (pp. 700-714). Oxford, UK: Oxford University Press.

Luthans, F. (2002a). Positive organizational behavior: Developing and maintaining psychological strengths. Academy of Management Executive, 16, 57-72.

Luthans, F. (2002b). The need for and meaning of positive organizational behavior. Journal of Organizational Behavior, 23, 695-706.

Masten, A.S. \& Reed, M.G.J. (2002). Resilience in development In C.R. Snyder \& S.J. Lopez (Eds.). Handbook of positive psychology. (pp. 74-88). Oxford, UK: Oxford University Press.

Matarazzo, J.D. (1987). There is only one Psychology, no specialities, but many applications. American Psychologist, 42, 893-903.

McGeary, J. (2004). The scandal's growing stain. Time, 163 (20), $24-32$.

Meiring, D., Van de Vijver, A.J.R., Rothmann, S. \& Barrick, M.R. (2005). Construct, item, and method bias of cognitive and personality measures in South Africa. South African Journal of Industrial Psychology, 31 (1), 1-8.

Milgram, S. (1963). Behavioral study of obedience. Journal of Abnormal and Social Psychology, 67, 371-378.

Milgram, S. (1965). Liberating effects of group pressure. Journal of Personality and Social Psychology, 1, 127-134.

Milgram, S. (1974). Obedience to authority. New York: Harper.

Miller, E.J. (1993). From dependency to autonomy: Studies in organization and change. London: Free Association Books.

Moalusi, K.P. (2001). Repositioning Industrial Psychology for the creation of new futures in turbulent times. South African Journal of Industrial Psychology, 27 (4), 17-21.

Myers, D.G. (2000). The funds, friends, and faith of happy people. American Psychologist, 55, 56-67.

Neumann, J.E., Kellner, K. \& Dawson-Shepherd, A. (1997) Developing organisational consultancy. London: Routledge.

Oakland, T. (2004). Use of educational and psychological tests internationally. Applied Psychology: An International Review, 53, 157-172.

Obholzer, A. \& Roberts, V.Z. (1994). The unconscious at work. London: Routledge.

Peltier, B. (2001). The psychology of coaching. Theory and application. New York: Brunner-Routledge.

Pienaar, J. (2002). Coping, stress and suicide ideation in the South African Police Service. Unpublished doctoral thesis, Potchefstroom University for CHE, Potchefstroom.

Pienaar, Y. \& Roodt, G. (2001). The current and future roles of Industrial Psychologists in South Africa. South African Journal of Industrial Psychology, 27 (4), 25-33.

Pietersen, H.J. (1989). An epistemological view of industrial /organisational psychology: Some perspectives and implications for future knowledge development. South African Journal of Industrial Psychology, 19 (2), 101-108.

Renecle, S.D. (2001). The relevance of Industrial Psychology as a profession and discipline in South Africa. South African Journal of Industrial Psychology, 27 (4), 22-24.

Robbins, S.P., Odendaal, A. \& Roodt, G. (2003). Organisational behaviour: Global and South African perspectives. Cape Town: Pearson Education.

Robertson, G.J. (1990). A practical model for test development. In C.R. Reynolds \& R.W. Kamphaus (Eds.), Handbook of psychological and educational assessment of children: Intelligence and achievement (pp. 62-85). New York: The Guilford Press.

Rothmann, S. (2003). Burnout and engagement: A South African perspective. South African Journal of Industrial Psychology, 29 (4), 16-25. 
Ryan, A.M. (2003). Defining ourselves: I/O psychology's identity quest. The Industrial-Organizational Psychologist, 41 (1), 21-33.

Salovey, P., Mayer, J.D. \& Caruso, D. (2002). The positive psychology of emotional intelligence. In C.R. Snyder \& S.J. Lopez (Eds.). Handbook of positive psychology. (pp. 159-171). Oxford, UK: Oxford University Press.

Savicki, V. (2002). Burnout across thirteen cultures: Stress and coping in child and youth care workers. Westport, CT: Preager.

Schaufeli, W.B. (2003). Past performance and future perspectives of burnout research. South African Journal of Industrial Psychology, 29 (4), 1-15.

Schaufeli, W.B. \& Bakker, A.B. (2001). Werk en welbevinden: Naar een positieve benadering in de Arbeids- en Gezondheidspsychologie [Work and wellbeing: Towards a positive occupational health psychology]. Gedrag en Organizatie, 14, 229-253.

Schaufeli, W.B. \& Bakker, A.B. (2004). Job demands, job resources and their relationship with burnout and engagement: A multisample study. Journal of Organizational Behavior, 25, 293-315.

Schneider, K.J., Bugental, J.F.T. \& Pierson, J.F. (2001). The handbook of humanistic psychology. Thousand Oaks, CA: Sage.

Schreuder, A.M.G. (2001). The development of Industrial Psychology at South African Universities: A historical overview and future perspective. South African Journal of Industrial Psychology, 27 (4), 2-7.

Seligman, M.E.P. \& Csikszentmihalyi, M. (2000). Positive psychology: An introduction. American Psychologist, 55, 5-14.

Seligman, M.E.P. (2002). Authentic happiness: Using the new positive psychology to realize your potential for lasting fulfillment. London: Nicholas Brealey.

Snyder, C.R. \& Lopez, S.J. (2002). Handbook of positive psychology. Oxford, UK: Oxford University Press.

Sonnentag, S. (2003). Recovery, work engagement, and proactive behavior: A new look at the interface between nonwork and work. Journal of Applied Psychology, 88, 518-528.

Sperry, L. (2004). Executive coaching. The essential guide for mental health professionals. New York: Brunner-Routledge

Stanton, A.L., Parsa, A. \& Austenfeld, J.A. (2002). The adaptive potential of coping through emotional approach. In C.R. Snyder \& S.J. Lopez (Eds.). Handbook of positive psychology. (pp. 148-158). Oxford, UK: Oxford University Press.

Stapley, L.F. (1996). The personality of the organisation. London: Free Association Books.
Strümpfer, D.J.W. (1990). Salutogenesis: A new paradigm. South African Journal of Psychology, 20, 265-276.

Strümpfer, D.J.W. (1995). The origins of health and strength: From 'salutogenesis' to 'fortigenesis'. South African Journal of Psychology, 25, 81-89.

Triandis, H.C. (2003). The future of workforce diversity in international organizations: A commentary. Applied Psychology: An International Review, 52, 496-495.

Turner, N., Barling, J. \& Zacharatos, A. (2002). Positive psychology at work. In C.R. Snyder \& S.J. Lopez (Eds.), Handbook of positive psychology. (pp. 715-728). Oxford, UK: Oxford University Press.

Tyler, G. (2002). A review of the $15 F Q+$ Personality Questionnaire. Pulloxhill, UK: Psychometrics Limited.

Van de Vijver, F. \& Leung, K. (1997). Methods and data-analysis for cross-cultural research. Thousand Oaks, CA: SAGE.

Van Hemert, D. A. (2003). Patterns of cross-cultural differences in psychology: A meta-analytic approach. Unpublished doctoral dissertation, Tilburg University, The Netherlands.

Veldsman, T. (2001). A new playing field, game and/or different rules? Into the future with Industrial Psychology as a discipline and profession. South African Journal of Industrial Psychology, 27 (4), 34-41.

Warr, P. (1984). Economic recession, and mental health: A review of research. Tijdschrift voor Sociale Gezondheidszorg, 62, 298-308.

Watkins, M.L. (2001). Industrial Psychology: An identity crises and future direction. South African Journal of Industrial Psychology, 27 (4), 8-13.

Watson, D. (2002). Positive affectivity: The disposition to experience pleasurable emotional states. In C.R. Snyder \& S.J. Lopez (Eds.). Handbook of positive psychology (pp. 106-119). Oxford, UK: Oxford University Press.

Wright, T.A. \& Cropanzano, R. (2000). The role of organizational behaviour in occupational health psychology: A view as we approach the millennium. Journal of Occupational Health Psychology, 5, 5-10.

Wright, T.A. \& Wright, V.P. (2002). Organizational researcher values, ethical responsibility, and the committed to participant perspective. Journal of Management Inquiry, 11, 173-185.

Wright, T.A. (2003). Positive organizational behavior: An idea whose time has truly come. Journal of Organizational Behavior, 24, 437-442. 